\title{
L'elaboració de sabó casolà com a eina per construir el model Canvi Químic.
}

Glòria Lozano Mena (gloria.lozano.mena@gmail.com) Màster en Professorat d'ESO i Batxillerat a la Universitat Autònoma de Barcelona (UAB)

En aquest article es presenta el disseny i la implementació d'una Unitat Didàctica (UD) titulada "D'oli brut a sabó: màgia, física o química?", que versa sobre el model canvi químic. La UD ha estat contextualitzada en l'elaboració de sabó a partir d'oli de cuina usat, una experiència senzilla però molt il/lustrativa, que permet treballar diversos aspectes d'aquest model científic.

Paraules clau: canvi químic, sabó, oli brut, laboratori, experiments.

This article presents the design and implementation of a didactic unit entitled "From used cooking oil to soap: magic, Physics or Chemistry?" which deals with the chemical change model. The didactic unit has been contextualized in the making of soap from used cooking oil, a simple but very illustrative experience that allows working several aspects of this scientific model.

Paraules clau: chemical change, soap, used cooking oil, laboratory, experiments.

\section{INTRODUCCIÓ}

El model canvi químic és un dels continguts clau en l'àmbit cientificotecnològic del currículum de l'ESO [1] i és de gran rellevància ja que permet explicar les transformacions que experimenta la matèria o les substàncies del nostre entorn. L'objectiu últim de la UD "D'oli brut a sabó: màgia, física o química?", que aquí es presenta, és contribuir que l'alumnat construeixi aquest model científic, tot usant un context proper i atractiu.

Aquest treball s'ha dut a terme en el marc del Pràcticum del Màster de Formació de Professorat de Secundària (Universitat Autònoma de Barcelona), i el centre educatiu en el qual s'ha aplicat ha estat l'institut públic Rovira-Forns de Santa Perpètua de Mogoda (Barcelona). Concretament, aquesta UD s'ha impartit als alumnes de tercer d'ESO, al llarg de 8 sessions d'una hora cadascuna, entre els mesos de març i abril del curs acadèmic 20152016.
Per al disseny de la UD es va prendre com a punt de partida els continguts que es recullen en la Taula 1:

\section{CONTINGUTS CONCEPTUALS}

C1: Caracterització dels canvis físics i els canvis químics

C2: Identificació dels components d'una reacció química (reactius, productes)

C3: Interpretació de la reacció química com un procés de reagrupament dels àtoms que conformen les substàncies inicials (reactius) per donar lloc a unes substàncies diferents (productes). Conservació de la massa C4: L'enllaç químic com a determinant de les propietats de les substàncies

C5: Les regles de proporcionalitat que regeixen les reaccions químiques: concepte de mol, estequiometria, Reactiu limitant/en excés C6: Intercanvi d'energia de les reaccions químiques amb l'entorn: reaccions endotèrmiques/exotèrmiques

C7: Química dels sabons i detergents: mecanisme del procés de neteja

C8: Identificació del material de laboratori utilitzat

C9: Reconeixement de les etiquetes de seguretat dels reactius de laboratori i relació amb les mesures de prevenció adequades 


\section{CONTINGUTS PROCEDIMENTALS}

P1: Elaboració de sabó a partir d'oli de cuina usat

P2: Realització de reaccions químiques al laboratori. Comprovació experimental de la llei de conservació de la massa (en reaccions sense participació de gasos) i de l'intercanvi d'energia amb el medi

P3: Representació de les reaccions químiques en forma d'equacions igualades

P4: Resolució de problemes quantitatius per mitjà de l'aplicació de factors de conversió

P5: Anàlisi d'un text de divulgació científica sobre sabons i detergents P5: Elaboració de material escrit divulgatiu (pòster)

\section{CONTINGUTS ACTITUDINALS}

A1: Conscienciar-se de la importància de la recollida selectiva de l'oli usat

A2: Aprendre a treballar en un laboratori de Química: manipulació correcta de material i productes, respecte de les normes de seguretat i de comportament

Taula 1. Continguts conceptuals, procedimentals i actitudinals que es treballen en la UD "D'oli brut a sabó: màgia, física o química?".

Seguidament, l'atenció es va centrar a cercar un context que permetés treballar tots els aspectes mencionats anteriorment $\mathrm{i}$ que, alhora, estimulés l'interès i la participació de l'alumnat. Es va escollir l'elaboració de sabó casolà a partir d'oli de cuina usat perquè es tracta d'una reacció química que és senzilla però, alhora, permet una interpretació teòrica assequible per als alumnes d'ESO (Mans, 2008). En aquest sentit, un dels punts forts d'aquesta reacció és que il॰lustra clarament el canvi de propietats de les substàncies implicades: I'oli embruta i el sabó neteja. Això pot ser útil per evidenciar les diferències entre el canvi químic (canvi en les propietats intensives) i el canvi físic (es mantenen les propietats intensives, canvi en les propietats extensives). A més, el context d'elaboració del sabó casolà permet un elevat grau d'implicació dels alumnes, tant pel fet que han de recollir oli brut de casa com també perquè s'obté un producte útil que es poden endur.

L'elaboració del sabó casolà és una experiència molt estesa entre centres educatius de Catalunya, si bé generalment es tracta d'una activitat pràctica puntual, de caire lúdic 0 amb finalitats solidàries $[2$, $3,4,5,6]$. En l'altre extrem, l'elaboració de sabó també es pot arribar a plantejar com un problema obert, en el qual els alumnes no disposin d'un protocol establert sinó que hagin de fer una petita investigació sobre quin és el procediment més adequat per obtenir els millors resultats (Sánchez, 2000).
Finalment, en aquest context també es pot abordar un altre tema de gran rellevància, que és la consciència mediambiental, centrada particularment en els efectes contaminants de l'oli i com es poden evitar per mitjà de l'aprofitament d'aquest residu.

\section{DESCRIPCIÓ DE L’EXPERIÈNCIA DIDÁCTICA}

La UD es va estructurar intentant reflectir el cicle d'aprenentatge proposat per Jorba i Sanmartí (1994), és a dir, amb una primera fase d'exploració d'idees prèvies, seguit de la introducció de nous punts de vista, la síntesi i estructuració dels nous coneixements $\mathrm{i}$, finalment, la seva aplicació. Els continguts que es pretenien treballar es van agrupar segons afinitats $i$ es van seqüenciar temporalment tot seguint un ordre de dificultat creixent; també, es va tenir en compte el temps del qual es disposava per impartir la UD (8 sessions d'una hora de durada). Així, es van dissenyar un total de 7 activitats (Taula 2), cadascuna de les quals es materialitzava en una fitxa que s'entregava a l'alumnat a l'inici de cada sessió. Les fitxes incloïen tant exercicis que es resolien a classe o a casa, com també requadres informatius, com el que es mostra en la Figura 1. Totes les sessions van ser dirigides pel professor, que marcava els exercicis que s'han de dur a terme i moderava la posterior posada en comú i correcció.

\begin{tabular}{|c|c|c|}
\hline & TÍTOL DE L'ACTIVITAT & $\begin{array}{l}\text { FASES DEL CICLE } \\
\text { D'APRENENTAGE }\end{array}$ \\
\hline $\begin{array}{c}\text { Activitat } \\
1(1 \mathrm{~h})\end{array}$ & Què en fem, de l'oli de cuina usat? & EXPLORACIÓ \\
\hline $\begin{array}{l}\text { Activitat } \\
2(1 \mathrm{~h})\end{array}$ & Sabonaires per un dia & \multirow{4}{*}{$\begin{array}{c}\text { INTRODUCCIÓ } \\
\text { DE NOUS PUNTS } \\
\text { DE VISTA }\end{array}$} \\
\hline $\begin{array}{c}\text { Activitat } \\
3(1 \mathrm{~h})\end{array}$ & Canvi físic o canvi químic? & \\
\hline $\begin{array}{c}\text { Activitat } \\
4(1 \mathrm{~h})\end{array}$ & Un dia al laboratori de Lavoisier & \\
\hline $\begin{array}{c}\text { Activitat } \\
5(2 h)\end{array}$ & $\begin{array}{l}\text { Les reaccions químiques, un joc } \\
\text { d'atzar o d'estratègia? }\end{array}$ & \\
\hline $\begin{array}{l}\text { Activitat } \\
6(1 \mathrm{~h})\end{array}$ & $\begin{array}{l}\text { Per què l'oli embruta i el sabó } \\
\text { neteja? }\end{array}$ & $\begin{array}{c}\text { SÍNTESI I } \\
\text { ESTRUCTURACIÓ }\end{array}$ \\
\hline $\begin{array}{l}\text { Activitat } \\
7(1 \mathrm{~h})\end{array}$ & Sabó i ciència per a tothom & $\begin{array}{l}\text { GENERALITZACIÓ } \\
\text { I APLICACIÓ }\end{array}$ \\
\hline
\end{tabular}




\section{Activitat 1}

L'activitat 1 té per objectiu reflexionar sobre els hàbits domèstics dels alumnes entorn de l'eliminació de l'oli de cuina usat, tot emfatitzant que es tracta d'un residu urbà altament contaminant i de difícil tractament. Després d'una breu, i dirigida, cerca a Internet sobre la correcta gestió d'aquest residu [7] es posa el focus en estratègies d'aprofitament de l'oli brut [8], entre les quals destaca, per la seva senzillesa i quotidianitat, l'elaboració de sabó casolà. En aquest punt es demana als alumnes que vegin a casa un vídeo divulgatiu [9] en el qual s'explica pas a pas el procediment, incloent les mesures de seguretat pertinents, a fi de preparar l'activitat de laboratori en la qual s'elaborarà el sabó (activitat 2); a més, s'anima els alumnes que recullin oli brut de casa i el portin filtrat, així com també possibles additius (colorants, aromes, flors seques, etc.).

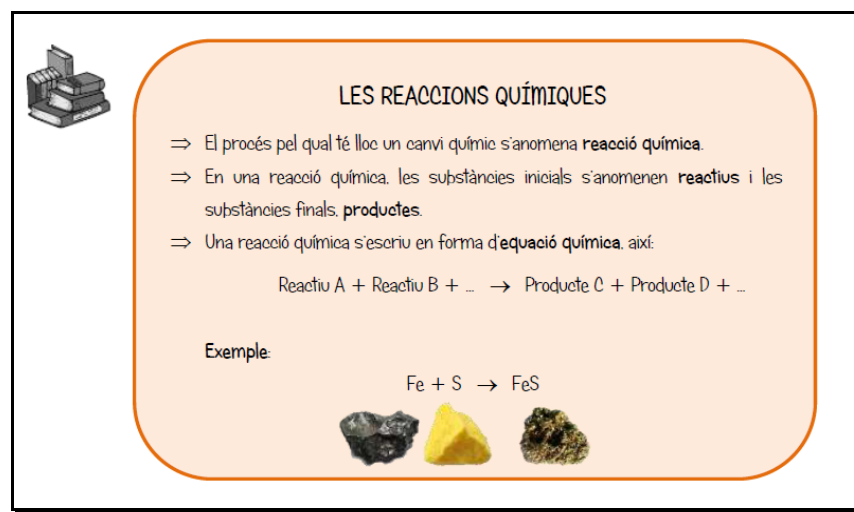

Figura 1: Exemple de requadre informatiu que els alumnes troben en les fitxes que se'ls entreguen.

\section{Activitat 2}

El dia que es duu a terme l'elaboració de sabó són els mateixos estudiants els que van dirigint el procés (Figures 2 i 3), tot recordant les pautes i precaucions presentades en el vídeo. Cal dir que en el nostre cas aquesta activitat es va fer dues vegades per a cada grup classe, en cadascuna de les quals hi havia la meitat dels alumnes.

\section{Activitat 3}

Un cop feta aquesta introducció, el primer que es treballa pel que fa als continguts curriculars és la diferenciació entre canvis físics i canvis químics. Inicialment es demana als alumnes que classifiquin els fenòmens que es recullen en la Figura 4 segons els seu propi criteri. És interessant fer una posada en comú dels resultats d'aquesta activitat per tal d'evidenciar la disparitat d'opinions. Després, el/la professor/a demana que tornin a fer la classificació en funció d'un criteri únic: en cadascuna de les situacions presentades, les substàncies presents abans i després del canvi són les mateixes o són diferents? Seguidament, es defineixen conceptualment els canvis físics i els canvis químics, i es duu a terme una petita activitat d'avaluació, en la qual els alumnes, en grups de tres o quatre, han de pensar i presentar davant de la resta nous exemples de canvis físics i químics que pot experimentar una substància.

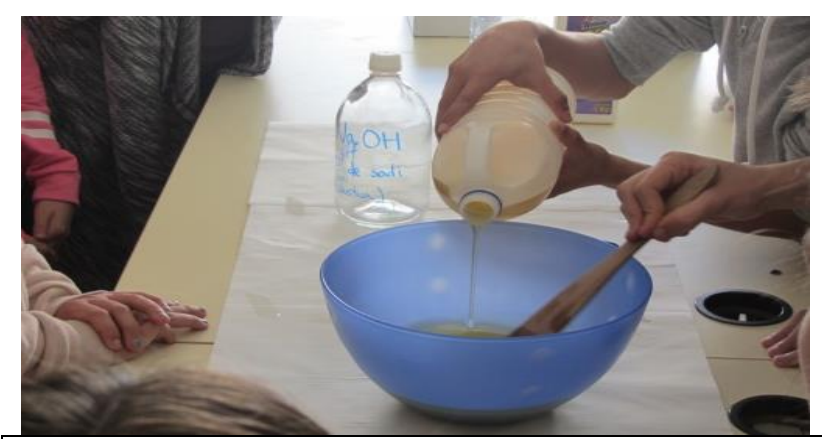

Figura 2. Elaboració de sabó casolà al laboratori.

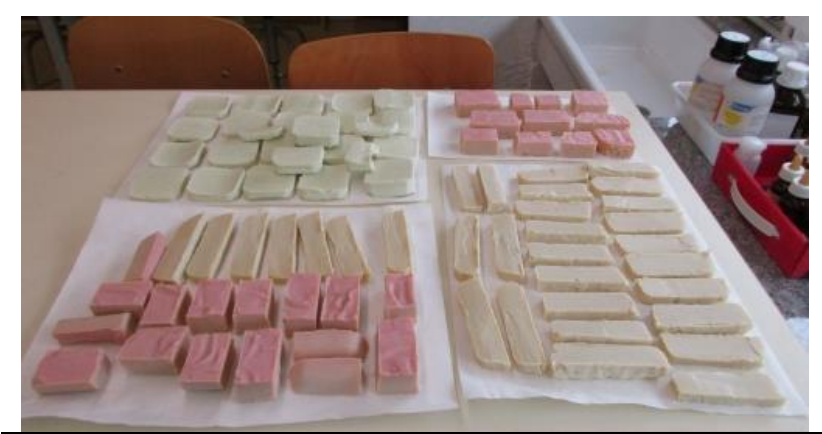

Figura 3. Un cop solidificat i tallat, cal deixar reposar el sabó unes sis setmanes.

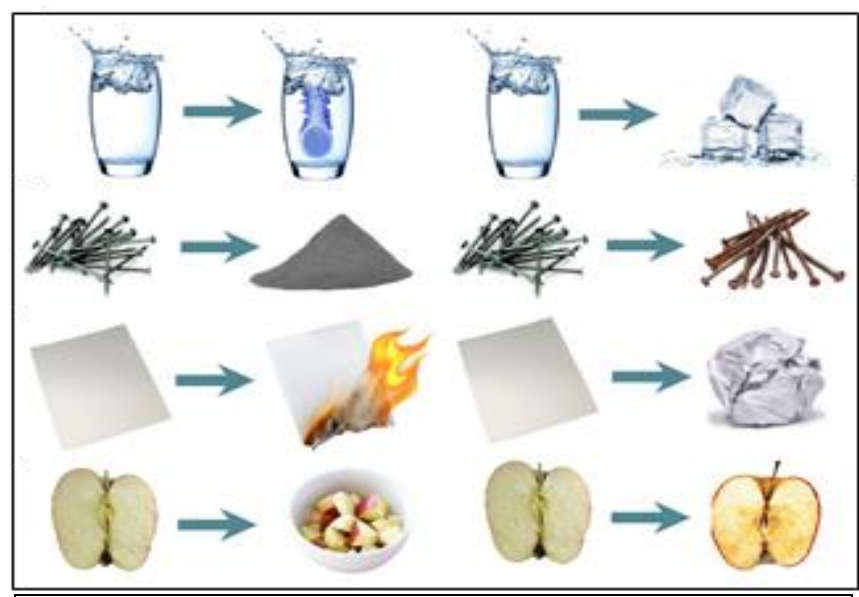

Figura 4. Exemples de canvis físics i químics quotidians emprats en l'activitat 3 de la UD. 
A continuació, i servint de base per a l'activitat 4 , es defineix el concepte de reacció química i es presenten els termes de "reactius" i productes", així com també les equacions químiques com a forma de representació de les reaccions (Figura 1).

\section{Activitat 4}

L'activitat 4 és una segona sessió de laboratori, en la qual els alumnes, en grups reduïts, duen a terme una sèrie de reaccions químiques emprant productes propis d'un laboratori de Química Inorgànica (Figura 5). Concretament, aquestes reaccions són les següents: la reacció redox entre el zinc i l'àcid clorhídric, que cursa amb despreniment d'hidrogen; la precipitació del clorur de plata, com a resultat de barrejar nitrat de plata i clorur de sodi; la precipitació del iodur de plom, a partir de nitrat de plom i iodur de potassi; i una reacció àcid-base amb efervescència, entre l'hidrogencarbonat de sodi i l'àcid clorhídric.

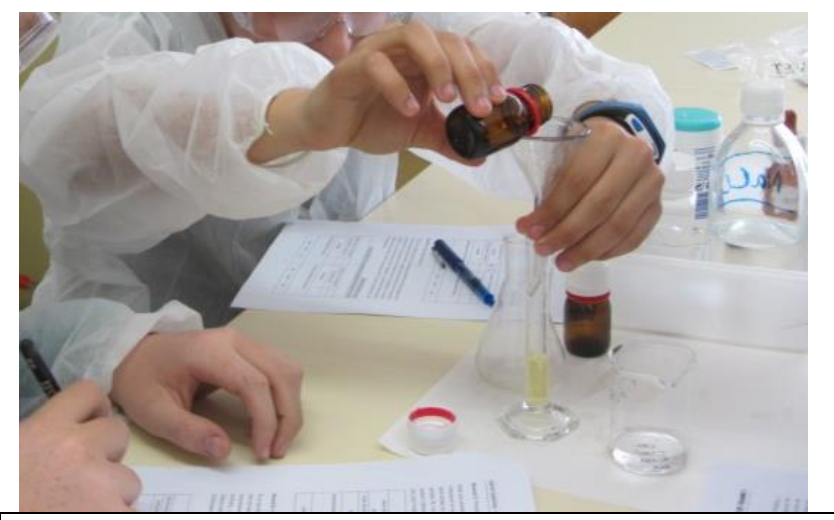

Figura 5. Realització d'experiments al laboratori de Química.

Per tal que en una única sessió, d'una hora de durada, es puguin dur a terme totes les reaccions anteriors, els experiments són totalment guiats: els alumnes disposen d'una fitxa en la qual es troben detallats els protocols de cada reacció (Figura 6), i a més, se'ls entrega una safata amb els reactius i el material de laboratori necessaris. És convenient, en la mesura del possible, proporcionar elements de protecció individual als alumnes, és a dir, bates, ulleres de seguretat i guants, per tal d'emular les condicions en les quals es treballa en laboratoris de recerca professionals. L'interès d'aquesta activitat, més enllà que els alumnes es familiaritzin amb el treball de laboratori, rau en la recollida de dades experimentals per a la seva posterior anàlisi. Així, els alumnes han d'anotar, a la taula que acompanya el protocol (Figura 6), l'aspecte de les substàn- cies implicades en la reacció i també el pes dels reactius i els productes.

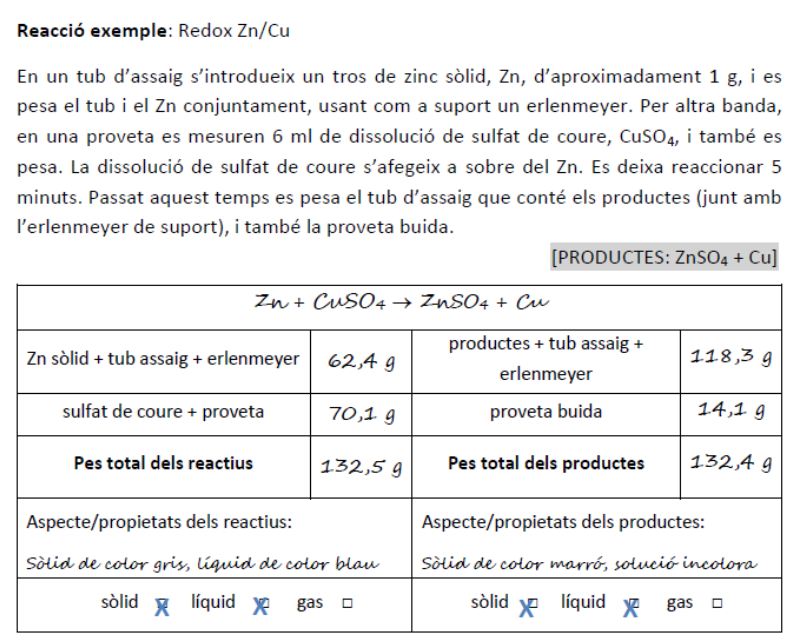

En un tub d'assaig s'introdueix un tros de zinc sòlid, $\mathrm{Zn}$, d'aproximadament $1 \mathrm{~g}$, i es pesa el tub $i$ el $\mathrm{Zn}$ conjuntament, usant com a suport un erlenmeyer. Per altra banda, en una proveta es mesuren $6 \mathrm{ml}$ de dissolució de sulfat de coure, $\mathrm{CuSO}_{4}$, i també es pesa. La dissolució de sulfat de coure s'afegeix a sobre del Zn. Es deixa reaccionar 5 minuts. Passat aquest temps es pesa el tub d'assaig que conté els productes (junt amb l'erlenmeyer de suport), i també la proveta buida.

\begin{tabular}{|c|c|c|c|}
\hline \multicolumn{4}{|l|}{$\bar{z}$} \\
\hline Zn sòlid + tub assaig + erlenmeyer & $62,4 \mathrm{~g}$ & $\begin{array}{c}\text { productes + tub assaig + } \\
\text { erlenmeyer }\end{array}$ & $118,3 \mathrm{~g}$ \\
\hline sulfat de coure + proveta & $70,1 \mathrm{~g}$ & proveta buida & $14,1 \mathrm{~g}$ \\
\hline Pes total dels reactius & $132,5 \mathrm{~g}$ & Pes total dels productes & $132,4 \mathrm{~g}$ \\
\hline \multicolumn{2}{|c|}{$\begin{array}{l}\text { Aspecte/propietats dels reactius: } \\
\text { Sotid de cotor gris, liquid de cotor blau }\end{array}$} & \multicolumn{2}{|c|}{$\begin{array}{l}\text { Aspecte/propietats dels productes: } \\
\text { Sòtid de cotor marró, solució incotora }\end{array}$} \\
\hline sòlid $\mathbb{X}$ líquid $X \mathrm{~g}$ & as $\square$ & sòlid $X$ líquid $X$ & as $\square$ \\
\hline
\end{tabular}

Figura 6. Exemple de reacció química que encapçala el guió proporcionat als alumnes en l'activitat 4.

\section{Activitat 5}

Les dades experimentals recollides anteriorment són objecte d'anàlisi en l'activitat 5 de la UD, que se centra en dos punts clau del canvi químic:

- En tota reacció es produeix un canvi en les propietats de les substàncies que hi intervenen (en els casos que ens ocupen, es tracta de propietats observables a ull nu, com és un canvi de color o el despreniment de gasos); aquest fet és conseqüència de la diferent manera com els àtoms estan enllaçats en els reactius $i$ en els productes.

- Si no hi ha gasos implicats en la reacció química, la massa dels reactius és igual a la massa dels productes. Això es deu al fet que els àtoms que constitueixen els reactius són els mateixos que formen després els productes, i que en el transcurs de la reacció química el que ha tingut lloc és un reagrupament d'aquests àtoms.

Però què ocorre quan participen gasos en la reacció? Donada la seva naturalesa, els gasos tendeixen a expandir-se per tot l'espai disponible, per la qual cosa, si es treballa amb recipients oberts, no es pot determinar el pes de les substàncies gasoses. En aquest moment és convenient repetir un dels experiments que cursa amb despreniment de gasos, però ara "atrapant" el gas tot col•locant un globus en el coll del recipient. 
Reprenent la idea que els àtoms que conformen els reactius són els mateixos que es troben en els productes, tot seguit es treballa breument la igualació d'equacions químiques senzilles. I no es pot tancar aquest apartat sense explicar que en un laboratori de Química no es manipulen àtoms aïllats, sinó quantitats de l'ordre de grams, per la qual cosa s'introdueixen en aquest punt els conceptes de mol i pes molecular.

Un darrer aspecte que es tracta en l'activitat 5 és l'intercanvi d'energia entre les reaccions químiques i l'entorn, si bé la dificultat conceptual que implica ha promogut que s'abordi únicament des d'un punt de vista pràctic. Així, es parla de les begudes autoescalfables, en les quals es produeix un despreniment de calor, i les bosses de fred instantani, que cursen amb absorció de calor (i per tant, es percep que es refreden). En ambdós casos el mecanisme de funcionament és el mateix: es trenca una barrera física que separa dues substàncies contingudes en diferents compartiments de l'envàs, i això té com a conseqüència una reacció química, exotèrmica o endotèrmica.

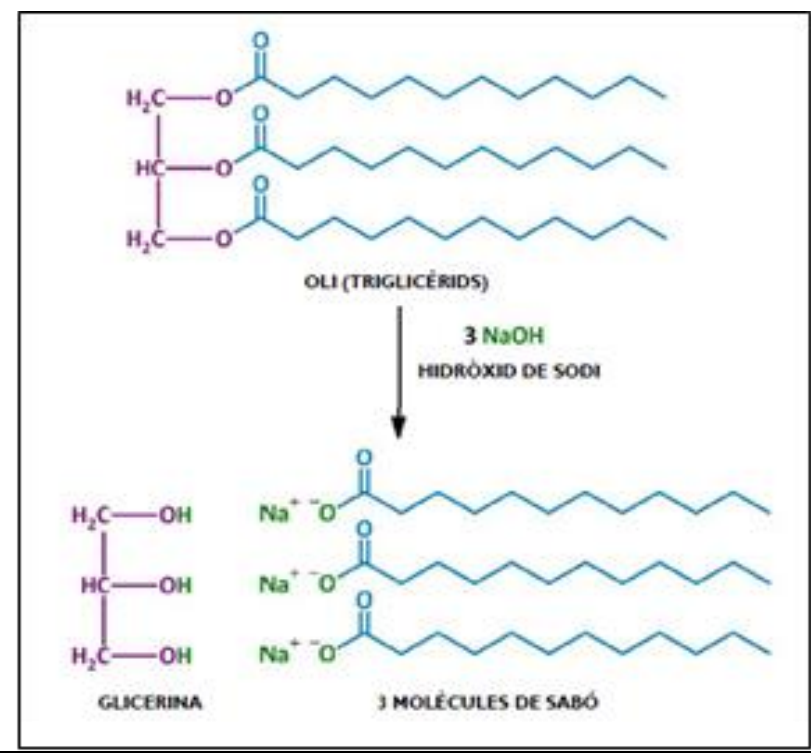

Figura 7. Reacció de saponificació dels triglicèrids, els principals components de l'oli, amb sosa càustica, que condueix a la formació de glicerina i molècules de sabó.

\section{Activitat 6}

L'activitat 6 de la UD posa el focus en les diferents propietats dels reactius i els productes, per la qual cosa la transformació de l'oli brut a sabó és un exemple excel•lent, ja que tenen propietats antagòniques: l'oli embruta i el sabó neteja. Per aprofundir en aquest aspecte es mostra als alumnes un esquema de la reacció de saponificació (Figura 7), en el qual s'aprecia la diferent manera com els àtoms s'enllacen en els reactius (triglicèrids de l'oli, hidròxid sòdic o sosa) i els productes (glicerina, molècules de sabó o tensioactiu). Cal fer èmfasi en l'aparició de l'enllaç iònic a l'extrem de les molècules de tensioactiu, que és el que permet la solubilització de les substàncies greixoses. Aquest procés de neteja s'explica de manera gràfica a través d'una seqüència de vinyetes.

\section{Activitat 7}

Finalment, la UD es tanca amb l'activitat 7 , que té per objectiu introduir als alumnes la divulgació científica com a mitjà per fer arribar la ciència a tota la població. Així, se'ls demana que recullin en un pòster tots els coneixements adquirits al llarg de les diferents sessions, proporcionant-los prèviament una pauta amb els continguts més rellevants. Aquesta tasca és una de les activitats avaluables de la UD, en concret a la qual s'ha donat un major valor, donat que abraça tots els aspectes treballats. La Taula 3 recull els criteris seguits per a l'avaluació dels pòsters

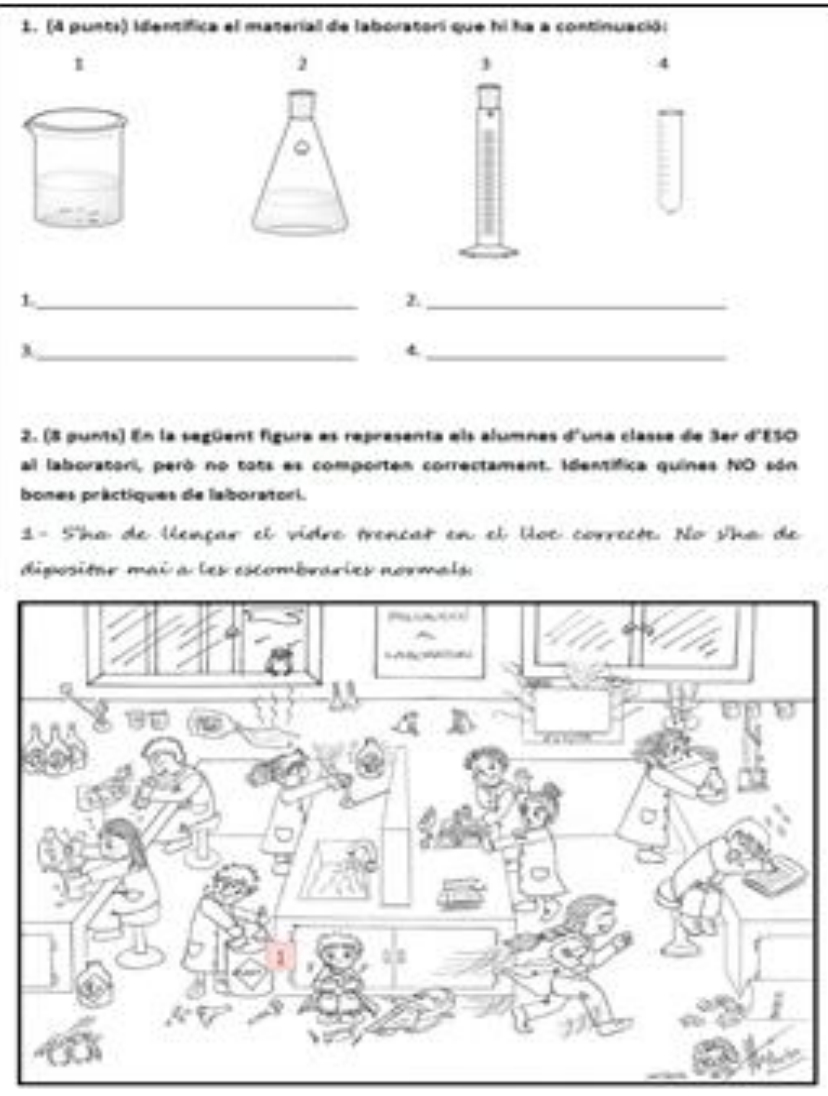

Figura 8. Activitat avaluable en la qual els alumnes han d'identificar material de laboratori i comportaments incorrectes en un laboratori de Química (Autora de la il-lustració: Marta Sánchez) 


\begin{tabular}{|c|c|c|}
\hline APARTATS & CRITERI D’AVALUACIÓ & $\begin{array}{l}\text { COMPLEIX } \\
\text { TOTALMENT } \\
\text { EL CRITERI }\end{array}$ \\
\hline Apartat 1.a & $\begin{array}{l}\text { Argumenta adequadament en favor de la recollida selectiva de l'oli de cuina } \\
\text { brut, parla de les conseqüències d'una mala gestió d'aquest residu }\end{array}$ & 1 \\
\hline Apartat 1.b & $\begin{array}{l}\text { Enumera } 4 \text { productes d'aprofitament de l'oli de cuina brut (sabó, biodièsel, pintu- } \\
\text { res, cosmètics) }\end{array}$ & 1 \\
\hline Apartat 2.a & $\begin{array}{l}\text { Fa una llista exhaustiva dels elements necessari per elaborar sabó casolà (in- } \\
\text { gredients, material). }\end{array}$ & 0,5 \\
\hline Apartat 2.b & Explica en detall els passos del procediment d'elaboració de sabó. & 0,5 \\
\hline Apartat 2.b & Justifica les precaucions que cal prendre. & 0,5 \\
\hline Apartat 3 & $\begin{array}{l}\text { Aplica el model canvi químic per explicar la transformació d'oli brut a sabó (con- } \\
\text { servació de la massa, reagrupament d'àtoms, enllaços diferents, regles de pro- } \\
\text { porcionalitat) }\end{array}$ & 2 \\
\hline Apartat 4.a & Explica l'estructura de les molècules de sabó. & 1 \\
\hline Apartat 4.b & Explica com actua el sabó (formació de micel-les). & 1 \\
\hline Apartat 4.c & Utilitat específica del sabó (greix). & 0,5 \\
\hline $\begin{array}{l}\text { Correcció } \\
\text { lingüística }\end{array}$ & $\begin{array}{l}\text { El text està ben redactat, emprant termes científics, sense faltes ortogràfiques ni } \\
\text { gramaticals destacables. }\end{array}$ & 1 \\
\hline Presentació & El pòster és atractiu, els apartats es distingeixen clarament. & 1 \\
\hline TOTAL & & 10 \\
\hline
\end{tabular}

L'avaluació es completa amb altres activitats, més senzilles, com són les que es mostren en les Figures 8 i 9, i també amb una valoració de l'actitud i comportament de cada alumne a l'aula i al laboratori.

\begin{abstract}
(2 punts) Identifica Y'enllaç iònic que es forma com a conseqüència de la reacció de saponificació. Per què anomenem les regions de la molècula com "cap polar" i "cua apolar"?

(2 punts) L'oli és un greix i embruta; llavors com pot ser que un producte derivat d'aquest oli tingui la propietat contrària, és a dir, de netejar?

(2 punts)És correcte dir que el sabó que has obtingut conté oli?

(2 punts) Un alumne que ha fet aquesta Unitat Didàctica explica als seus avis que ha elaborat sabó a partir d'oli de cuina brut i sosa. Els avis li comenten que aquest sabó deu netejar molt millor que altres sabons perquè porta sosa (has de saber que la sosa es pot utilitzar per a la neteja de la llar, com a desembossador de canonades o brutícia molt incrustada). Estàs d'acord amb Yafirmació que fan els avis?

(2 punts) Imagina que treballes a la cuina d'un restaurant i que tens una pila de plats i trastos bruts per fregar. Els plats tenen restes d'una salsa que està feta amb una base de mantega, mentre que una de les olles, en la qual s'hi volia bullir arròs, té restes de sal que han quedat després que s'evaporés accidentalment tota l'aigua. Tenint en compte el que has après, netejaries de la mateixa manera, usant sabó, tant els plats com P'olla? Raona la teva resposta.
\end{abstract}

Figura 9: Activitat avaluable en la qual els alumnes han de respondre raonadament diferents preguntes entorn de les prioritats de l'oli i del sabó.

\section{VALORACIÓ}

La implementació de la UD "D'oli brut a sabó: màgia, física o química?" al curs de tercer d'ESO de l'institut Rovira-Forns ha tingut una bona acolli- da per part dels alumnes, que des l'inici s'han mostrat molt receptius a totes les activitats proposades. S'ha evidenciat que les tasques de caràcter pràctic, és a dir, l'elaboració de sabó i les reaccions químiques, capten notablement la seva atenció i fomenten la seva curiositat.

D'altra banda, l'aprenentatge que han fet els alumnes s'ha valorat per mitjà de dues eines: el pòster divulgatiu que han elaborat en l'activitat $7, \mathrm{i}$ també el Treball de Fi de Màster (TFM) (Lozano, 2016), en el qual s'ha fet una breu recerca sobre la influència que ha exercit la UD en la capacitat dels alumnes per identificar canvis químics en el seu entorn. Pel que fa els pòsters, s'ha vist que els alumnes no inclouen totes les idees treballades al llarg de la UD, si bé disposaven d'una pauta que marcava els continguts més rellevants. Donat que aquesta activitat l'han realitzat un cop finalitzada la intervenció didàctica, i que no ha estat supervisada, es desconeix si aquesta mancança es deu al fet que no han construït els coneixements o a una dedicació insuficient.

En segon lloc, en el marc del TFM s'ha demanat als alumnes, abans i després de la UD, que proporcionin exemples de fenòmens del seu entorn que pensin que són canvis químics. L'anàlisi de les respostes ha evidenciat que després de la UD els alumnes aporten una major quantitat d'exemples, que a més es contextualitzen en un major nombre d'àmbits: mentre que abans es concentraven en el medi ambient, i es tractava de grans canvis que tenen lloc a la natura (sobretot meteorològics), al final 
la llar és amb diferència l'àmbit més emprat pels estudiants, per la seva proximitat i perquè és un context ric en canvis químics. S'ha de dir, però, que els exemples que aporten els alumnes estan estretament lligats a la dinàmica d'aula: la majoria dels fenòmens havien estat presentats pel professorat 0 els companys de classe en alguna sessió, mentre que poc més del $20 \%$ han estat aportacions originals, mai comentades anteriorment.

Un darrer apunt valoratiu és que l'elaboració de sabó en aquesta UD podria emmarcar-se dins d'un projecte de més abast, en el qual tots els alumnes recollissin oli de la llar durant un període de temps més llarg, i que el sabó obtingut es pogués vendre a familiars i amics, i servís per subvencionar activitats de caire lúdic. Així mateix, podria arribar a esdevenir un projecte transversal, amb participació del professorat d'altres àrees.

\section{AGRAIIMENTS.}

El meu agraïment al Víctor López, tutor del Pràcticum, la Cristina Benaiges, companya en el disseny i la implementació de la UD, la Isabel Valverde, tutora a l'institut, i la Marta Sánchez, autora de la il•lustració.

\section{REFERÈNCIES.}

JORBA, J.; SANMARTÍ, N. (1994). Enseñar, aprender y evaluar: un proceso de evaluación continua. Madrid: Ministerio de Educación y Cultura. 321 pàgs.

LOZANO MENA, G. (2016). Treball de Fi de Màster: Canvis químics que identifiquen estudiants de tercer d'ESO en el seu entorn, abans $i$ després d'una unitat didàctica de química. Màster de Formació de Professorat d'Educació Secundària Obligatòria i Batxillerat, Formació Professional i Ensenyament d'Idiomes (Universitat Autònoma de Barcelona)
MANS, C. (2008). Química quotidiana. Educació Química, 1, 4-9

SÁNCHEZ GÓMEZ, P.J. (2000). Una propuesta innovadora para una pràctica tradicional: la elaboración de jabón como problema abierto. Anales de la Real Sociedad Española de Química. Segunda Época, enero-marzo, 1-8

\section{NOTES.}

[1] "Decret 187/2015, de 25 d'agost, d'ordenació dels ensenyaments de l'educació secundària obligatòria”. DOGC núm. 6945, de 28 d'agost de 2015

[2] INS Berenguer d'Entença (2016). L'elaboració de sabó per la marató de TV3 [article en línia]. INS Berenguer d'Entença. [Consultat el 10 de novembre de 2016]:

http://agora.xtec.cat/iesbde/eso/fer_sabo/

[3] INS Josep Lladonosa (2015). Elaboració de sabó solidari [article en línia]. INS Josep Lladonosa. [Consultat 10 de novembre de 2016]: http://www.insjoseplladonosa.cat/blog/2015/12/0 4/elaboracio-de-sabo-solidari/

[4] Institut Giola (2013). Taller de sabó ecològic [article en línia]. Institut Giola. [Consultat el 10 de novembre de 2016]:

http://www.institutgiola.org/ca/153187/galeria/Ta ller-sabo-ecologic.htm

[5] Martínez, Rosamaría (2014). Elaboració de sabó artesà a l'institut [article en línia]. Institut Europa. [Consultat el 10 de novembre de 2016]: https://www.ins-europa.org/index.php/9activitats/209-elaboracio-de-sabo-artesa-a-Iinstitut 